\title{
PRODUÇÃO TEXTUAL DE ALUNOS SURDOS INCLUÍDOS NO ENSINO MÉDIO: UM ESTUDO DE CASO
}

\author{
WRITTEN TEXTS OF INCLUDED HIGH-SCHOOL DEAF STUDENTS: A CASE STUDY
}

\author{
Osilene Maria de Sá e Silva da Cruz¹, Leila Lopes de Queiroz Gouveia² \\ 1 Instituto Nacional de Educação de Surdos (INES), Rio de Janeiro, RJ, Brasil \\ osilenesacruz@gmail.com \\ 2 Secretaria Municipal de Ensino do Rio de Janeiro, Rio de Janeiro, RJ, Brasil \\ leilocagouveia@gmail.com
}

Recebido em: 25 abr. 2018

Aceito em: 31 mai. 2018

\begin{abstract}
Resumo: Este artigo tem como objetivo analisar a produção escrita de três alunos surdos do Ensino Médio em escolas inclusivas no Rio de Janeiro. Mostra também a importância de o professor estimular a leitura e usar estratégias de ensino de Língua Portuguesa (LP) escrita, principalmente, por meio de recursos visuais e pela ativação do conhecimento prévio e de conhecimento de mundo, em Libras, primeiramente, de modo que o aluno tenha argumentos para desenvolver a escrita de forma eficiente. A temática sobre ensino de leitura e escrita para alunos surdos teve como base pesquisas sobre ensino de LP como L2 (LODI, 2004; PEREIRA, 2007; CRUZ, 2016, entre outros) e foi realizado um estudo de caso (GIL, 2002; 2008). Os resultados mostram que as diferentes estratégias utilizadas com os alunos interferiram diretamente na produção escrita dos aprendizes. Mostram também que a produção escrita do aluno surdo é resultado do processo de construção para atingir o amadurecimento linguístico na compreensão e produção textual.
\end{abstract}

Palavras-chaves: Educação inclusiva. Alunos surdos. Libras. Língua Portuguesa escrita. Ensino Médio.

\begin{abstract}
This article aims to analyze the written production of three deaf students from High School in inclusive schools situated in Rio de Janeiro. It also shows the importance of stimulating reading by the use of strategies on teaching written Portuguese language, mainly through visual resources and activation of prior knowledge and world knowledge, firstly, in Brazilian Sign Language - Libras, so that the student assimilates his arguments to develop writing efficiently. The subject around teaching strategies of reading and writing to deaf students had some studies as theoretical foundation on teaching Portuguese as a second language (LODI, 2004; PEREIRA, 2007; CRUZ, 2016, among others) and a case study was done (GIL, 2002; 2008). The results show that the different strategies used with the students interfered directly in learners' written texts. They also show that the written production of the deaf student is a result of a process that is constructed in direction to linguistic maturity on textual comprehension and production.
\end{abstract}

Keywords: Inclusive education. Deaf students. Libras. Portuguese Language. High school.

\section{Introdução}

Este artigo tem como objetivo principal apresentar um estudo sobre produção textual de alunos surdos do Ensino Médio. Para isso, relata a importância de estratégias diferenciadas de ensino de Língua Portuguesa escrita (LP) para esse público-alvo. Parte-se da experiência da autora do artigo, surda parcial e profissional, que se preocupa com a educação de surdos devido à condição de quem vivenciou, 
durante a vida escolar, os desafios e as dificuldades pelas quais passam aprendizes surdos ao terem contato com a língua portuguesa escrita.

No âmbito educacional, documentos têm sido importantes para a efetivação do processo inclusivo. A Declaração de Salamanca (UNESCO, 1994) estabeleceu condições para a Educação Inclusiva, visando não marginalizar e muito menos desfavorecer os alunos, destacando que as escolas devem respeitar o diferencial de cada um, principalmente na dificuldade de aprendizagem.

É necessário que a escola passe por adequação à realidade da inclusão, pois a inclusão é um direito de todos, ou seja, todas as pessoas com deficiência têm o direito de serem incluídas em salas regulares de ensino. Objetivamente, a ideia de promover a inclusão segue em direção à socialização de todos os envolvidos no processo escolar, promovendo sua integração e socialização dentro desse contexto.

Percebe-se, na atualidade, que os alunos surdos não são incluídos, pelo contrário, sua integração na escola leva-os à marginalização e ao desfavorecimento de suas vidas. Na verdade, promover educação inclusiva não significa apenas inserilos em um contexto escolar, mas, juntamente por essa ação, é importante oportunizar igualdades de condições, como qualquer cidadão para que possam ter as condições igualitárias aos ouvintes, em vários níveis: profissional, social, escolar, pessoal, etc (LODI, 2013).

Sobre isso, Quadros (2007) propõe a maneira como a inclusão pode garantir acesso à educação:

Dá para perceber que os surdos entendem a inclusão como garantia dos direitos de terem acesso à educação de fato consolidadas em princípios pedagógicos que estejam adequados aos surdos. As proposições ultrapassam as questões lingüísticas, incluindo aspectos culturais, políticos e educacionais. (QUADROS, 2007, p. 106)

Conforme posicionamento de Quadros (2007), é importante conhecer os sujeitos surdos e suas demandas, principalmente as linguísticas e pedagógicas, tornando-lhes acessíveis vários diretos, como a língua de sinais, os métodos, as estratégias adequadas e a adaptação curricular. Nesse sentido, é premente considerar que o surdo tem como L1 a Língua Brasileira de Sinais e deve se apoiar no seu direito, além do uso de recursos visuais. 
Sabe-se da importância da Libras como L1 e da Língua Portuguesa como L2, a partir do que propõe Lodi (2004, p.31) de que o surdo "Tem na L1 a base de compreensão e significação dos processos socioculturais, históricos e ideológicos que perpassam a L2". A pesquisadora também ressalta que os surdos não devem ser comparados aos falantes de uma língua majoritária como os ouvintes, ou seja, é preciso que seja compreendido o referencial de sua língua constitutiva na L1.

Atualmente, é comum vermos na rede pública de ensino, em escolas municipais e estaduais, aprendizes surdos com dificuldades para produzir textos escritos. Essas dificuldades podem ser decorrentes da falta de interesse, de estímulo, ou mesmo, de motivação para a compreensão, sendo a compreensão uma etapa anterior à produção do texto escrito. Esses alunos se tornam prejudicados com relação ao aprendizado de vocabulário e à ampliação de conhecimento de mundo.

Posto isso, o presente trabalho propõe uma reflexão sobre a produção escrita de alunos surdos incluídos. Mais especificamente, serão apresentadas análises de textos produzidos por três alunos surdos incluídos, matriculados em uma escola de Ensino Médio, situada na Baixada Fluminense do Rio de Janeiro, em Nilópolis. Na próxima seção, será apresentado o referencial teórico no qual este trabalho está amparado.

\section{Aspectos importantes da inclusão - de que inclusão estamos falando?}

A Lei de Diretrizes e Bases da Educação Nacional - LDB (BRASIL, 1996) estabelece para educação especial, em seu artigo 59, inciso III, que os sistemas de ensino assegurem aos educandos com deficiência:

III - professores com especialização adequada em nível médio ou superior, para atendimento especializado, bem como professores do ensino regular capacitados para integração desses educandos nas classes comuns. (BRASIL, 1996, ART. 59, INCISO III)

Partindo-se da perspectiva da LDB, é evidente que nem todos os professores têm essa especialização, pois a maioria dos cursos de formação de professores não os capacita para tal atuação. Todavia, destaca a importância do papel dos especialistas que atuarão nas diversidades de alunos com deficiência, por meio de um trabalho diferenciado, que deveria ser disponibilizado na escola. 
A Lei $N{ }^{\circ}$ 10.436, aprovada no dia 24 de abril de 2002, reconhece a Língua de Sinais - Libras - como língua do sujeito surdo, no artigo 10: "É reconhecida como meio legal de comunicação e expressão a Língua Brasileira de Sinais - Libras” (BRASIL, 2002). Desde que a Libras foi oficializada e com sua regulamentação pelo Decreto 5.626/2005, são evidentes alguns ganhos para a comunidade surda, no sentido de que as instituições de ensino devem possibilitar recursos humanos e estruturais adequados para aprendizes surdos. Então, passou-se a pensar na formação inicial e continuada do professor para atuar com aprendizes surdos ou com baixa audição. Além disso, são importantes estratégias de ensino e o uso de recursos visuais nos ambientes escolares e em outros contextos: comunidade, hospitais e repartições públicas.

A Declaração de Salamanca (UNESCO, 1994), como se vê abaixo, já destacava essa importância:

\begin{abstract}
Linha de Ação da Declaração no capítulo II, artigo 21, os alunos surdos devem ter atendimento específico:

21. As políticas educativas deverão levar em conta as diferenças individuais e as diversas situações. Deve ser levada em consideração, por exemplo, a importância da linguagem ${ }^{1}$ de sinais como meio para surdos, a ser assegurado a todos os surdos acesso ao ensino de linguagem dos sinais de seu país. Face às necessidades específicas de comunicação de surdos e de surdos cegos, seria mais conveniente que a educação lhes fosse ministrada em escolas especais ou em classes ou unidades especiais nas escolas comuns. (UNESCO, 1994)
\end{abstract}

Esse olhar da Declaração de Salamanca considera a Libras como a língua dos surdos e mostra sua relevância na comunicação e na socialização desses sujeitos, pois sabemos que a língua de sinais é um recurso e um instrumento primordial na educação, seja ela em regime de educação inclusiva ou bilíngue.

Apesar da exigência da Libras na proposta da educação inclusiva, nem todos os profissionais a dominam. O Decreto $N .-5.626$, regulamentado no dia 22 de dezembro de 2005, estabelece que os graduandos aprendam Libras durante o processo de formação acadêmica. No capítulo II, estabelece:

Art. 3o A Libras deve ser inserida como disciplina curricular obrigatória nos cursos de formação de professores para o exercício do magistério, em nível médio e superior, e nos cursos de Fonoaudiologia, de instituições de ensino, públicas e privadas, do sistema federal de ensino e dos sistemas de ensino dos Estados, do Distrito Federal e dos Municípios.

${ }^{1}$ A expressão linguagem de sinais deve ser entendida como língua de sinais. 
$\S 1$ 1o Todos os cursos de licenciatura, nas diferentes áreas do conhecimento, o curso normal de nível médio, o curso normal superior, o curso de Pedagogia e o curso de Educação Especial são considerados cursos de formação de professores e profissionais da educação para o exercício do magistério.

§ 2o A Libras constituir-se-á em disciplina curricular optativa nos demais cursos de educação superior e na educação profissional, a partir de um ano da publicação deste Decreto. (BRASIL, 2005, Art. 3o).

De acordo com o presente decreto, é necessário o ensino de Libras na formação docente, mesmo que não seja uma graduação específica nessa área. Portanto, os docentes deveriam ter formação inicial e continuada adequadas, o que somaria na sua construção de conhecimento, viabilizando a formação bilíngue. Analisando o referido decreto, percebemos algumas peculiaridades da garantia do direito das pessoas surdas ou com deficiência auditiva, pois o artigo 22 estabelece que a Educação Básica deve garantir a inclusão de surdos em escolas bilíngues, organizadas da seguinte maneira:

I - Escolas e classes de educação bilíngüe, abertas a alunos surdos e ouvintes, com professores bilíngües, na educação infantil e nos anos iniciais do ensino fundamental;

II - Escolas bilíngües ou escolas comuns da rede regular de ensino, abertas a alunos surdos e ouvintes, para os anos finais do ensino fundamental, ensino médio ou educação profissional, com docente das diferentes áreas de conhecimento, cientes da singularidade lingüística dos alunos surdos, bem como com a presença de tradutores e intérpretes de Libras - língua Portuguesa. (BRASIL, 2005)

Assim como no referido decreto e na Declaração de Salamanca (UNESCO, 1994), referenciada anteriormente, o documento Política Nacional de Educação Especial na Perspectiva da Educação Inclusiva, promulgado pela portaria no 948, de 09 de outubro de 2007, traz uma retrospectiva histórica da educação vivenciada por várias gerações no meio educacional, destacando a integração de forma socializada do educando e também propondo melhoria e qualidade de ensino. Conforme as diretrizes do referido documento, a educação inclusiva deve propiciar o ingresso dos alunos surdos na rede de ensino regular, dentro de uma proposta bilíngue, como se pode ver no trecho a seguir:

Para o ingresso dos alunos surdos nas escolas comuns, a educação bilíngüe - Língua Portuguesa/Libras desenvolve o ensino escolar na Língua Portuguesa e na Língua de Sinais, o ensino da Língua Portuguesa como segunda língua na modalidade escrita para alunos surdos, os serviços de tradutor/intérprete de Libras e Língua Portuguesa e o ensino da Libras para os demais alunos da escola. (BRASIL, 2007) 
Parece muito claro que os docentes devem buscar o conhecimento dessas duas línguas que efetivamente irão repercutir em alguns anos, nessa nova construção, e também na atuação dos profissionais intérpretes de Libras que assumem uma função mediadora dentro da escola e possibilitam a comunicação e interação entre alunos surdos e educadores, funcionários e gestores da escola.

No cenário educacional, é essencial que os surdos aprendam Libras e escrita. Com relação ao ensino de LP como L2, o que se observa é um discreto avanço das produções escritas, que deveriam ser estimuladas de modo a garantir a condição da visualidade, do uso de imagens, do letramento visual.

Dessa maneira, o ensino de português para alunos surdos como L2 deve ser compreendido na interpretação dos termos decodificados dentro do seu nível de conhecimento de mundo. Veremos neste artigo que os alunos apresentados são oralizados e usam constantemente a Libras. Essa condição de oralidade pode ser um reflexo por parte das famílias ouvintes que criam seus filhos com grandes estímulos para a oralização. Porém, a partir do momento em que esses alunos surdos adquirirem e usam a Libras nas escolas, passam a considera-la como prioridade na comunicação, ou seja, aquela com a qual eles se sentem confortáveis e por meio da qual se comunicam mais eficientemente.

Percebe-se na sala de aula grande despreparo dos profissionais docentes para atuarem na educação de surdos, especificamente, com o ensino de compreensão e produção textual Podemos perceber as questões da escrita dos alunos surdos, principalmente na rede pública, no Ensino Fundamental e Ensino Médio, em turmas inclusivas, pois grande parte dos docentes não tem conhecimento sobre como trabalhar com esses alunos. Sobre a formação docente, Mazzota (1993) destaca que:

\footnotetext{
A formação docente, ainda que não consiga preencher todas as lacunas vivenciadas no processo, ainda que quesito indispensável a preparação do professor atuar com responsabilidade na sala de aula. Uma vez que a formação do professor requer: fundamentação teórica, instrumentalização técnica e sensibilidade frente as implicações subjetivas que a atravessam a diversidade. (MAZZOTA, 1993, p. 40).
}

Diante do exposto, a formação inadequada do professor afeta diretamente a formação do aprendiz, por não contemplar a diversidade dos educandos, principalmente por serem os docentes desconhecedores da primeira língua dos 
surdos. No processo educacional no Ensino Médio, que é o foco deste trabalho, o cenário mostra que os currículos escolares são insatisfatórios para a aprendizagem do aluno surdo, principalmente o desenvolvimento da L2. No ambiente escolar, no contexto de turma inclusiva, a maioria dos docentes não desenvolve o trabalho de forma diferenciada, significativa e produtiva, o que tornaria o ensino uma instigação aos alunos surdos.

A escola inclusiva necessita reconhecer que o processo de ensino deve ocorrer em duas línguas diferentes, compreendendo-se as especificidades dos alunos surdos, principalmente dentro de uma política linguística (Libras-L1/LP-L2). Lodi e Moura (2006) enfatizam esta questão:

\footnotetext{
Em termos gerais, esta educação considera que, inicialmente, os surdos devam desenvolver a língua de sinais como primeira língua (L1), no contato com surdos adultos usuários da língua participantes ativos do processo educacional de seus pares. A partir da L1, os surdos são expostos ao ensino da escrita da língua majoritária, e para tal, toma-se como base os estudos sobre ensino-aprendizagem de segunda língua (L2) e os trabalhos sobre ensino de línguas estrangeiros. (LODI e MOURA, 2006, p. 02).
}

As autoras se posicionam com relação ao desenvolvimento das duas línguas, que darão suporte aos surdos para a compreensão de textos e para a aquisição da L2, de modo que entendam a importância da escrita, pois a sociedade brasileira exige a compreensão de textos, de documentos escritos na vida cotidiana, como, por exemplo, contrato de trabalho, de imóvel, dentre outras atividades sociais e profissionais comuns no dia a dia desses agentes sociais. Dessa forma, a aquisição de LP escrita é uma tarefa que deve ser perseguida pelos professores, mostrando aos discentes surdos a sua importância como língua majoritária e que não poderá ser substituída por nenhuma outra língua ou manifestação linguística no território brasileiro.

Tendo em vista a importância da Língua Portuguesa para os alunos surdos, na próxima seção, discutiremos o ensino dessa língua para surdos no Ensino Médio.

\section{Língua Portuguesa escrita no Ensino Médio}

A importância do ensino de LP escrita no Ensino Médio se justifica, principalmente, devido ao anseio dos alunos para o ingresso ao Ensino Superior. 
Entretanto, observa-se nesse nível escolar a necessidade de desenvolvimento da capacidade de argumentação, de expressão de opinião crítica, que deve ser desenvolvida a partir de gêneros textuais diversos e por meio de estratégias adequadas, visando ao letramento e sua formação como agente crítico socialmente.

É preciso atentar para conceitos importantes relacionados a letramento e letramento visual (GESUELI e MOURA, 2006), pois o aprendiz surdo demanda de estratégias e metodologias de ensino por meio de gêneros textuais e recursos visuais que façam sentido à sua vivência, às suas práticas sociais, à sua cultura dentro de uma comunidade surda. Dessa forma, recai sobre o professor de Língua Portuguesa a responsabilidade de desenvolver no aprendiz habilidades de leitura e produção de textos, de modo a ampliar o conhecimento de mundo, dentro das temáticas abordadas nos dias atuais.

A realidade nos mostra, infelizmente, que os alunos (surdos e ouvintes) são avaliados nas escolas e também no Exame Nacional do Ensino Médio - ENEM. Sabese da exigência da habilidade escrita no ENEM, principalmente, da exigência da argumentação em textos escritos. A maioria dos surdos, porém, apresenta dificuldade de expressar suas ideias e seus argumentos sobre determinadas temáticas, uma vez que não tiveram desenvolvimento adequado e acesso à leitura sobre diversos temas que são desenvolvidos no referido exame. Isso, certamente, promoveria a produção escrita eficiente.

Com relação à leitura e à escrita dos alunos surdos, no cenário educacional, enfrenta-se uma demanda de desenvolvimento da LP escrita. Desde o início da jornada escolar, os aprendizes surdos apresentam dificuldades na habilidade de leitura, muitas vezes, porque o professor não utiliza estratégias de ensino adequadas que atendam a sua necessidade de aprendizagem. Cruz (2016) trata dessa questão, descrevendo atividades de leitura e escrita, em que a Libras e a Língua Portuguesa escrita são abordadas a partir de estratégias de ensino diferenciadas, partindo da concepção de que a Libras é a L1 do aluno surdo e a LP é a L2.

Uma situação recorrente e complexa desenvolvida por professores de alunos surdos é pensar no ensino de LP por meio de textos e orações totalmente descontextualizadas, baseado na gramática tradicional e estruturalista, e essa prática perpassa por todas as etapas escolares. Ocorre, assim, um disfarce na aprendizagem, pois são limitados os recursos que explorem a capacidade de memória visual dos 
alunos surdos, o que faz com que eles assimilem a escrita das palavras, desconstruindo tudo o que seria importante para o letramento ou a compreensão do texto como um todo.

Logo, o docente de LP escrita, ao se deparar com a realidade da leitura e da escrita dos alunados surdos, deveria reconhecer que é um processo distinto do que ocorre com alunos ouvintes, usando em suas estratégias o conceito de letramento, articulando a leitura e a escrita com o letramento visual, para que esses alunos possam adquirir o conhecimento. Sobre a importância do letramento, Campos (2004) ressalta que:

As práticas de letramento estão diretamente relacionadas às atividades de leitura e escrita e às estruturas sociais em que se encontram, por isso elas mudam conforme o contexto. Essas práticas revelam os diferentes modelos culturais de utilização da linguagem escrita que se fazem presente nas atividades mais simples do cotidiano das pessoas (...). As pessoas constroem o seu entendimento sobre o letramento internamente e, ao mesmo tempo, utilizam as práticas para caracterizar os processos sociais que unem as pessoas na transmissão de ideologias e identidades sociais (CAMPOS, 2004, p. 40).

O contexto educacional demanda do profissional conhecimento e desenvolvimento de recursos para serem utilizados adequadamente no processo de ensino-aprendizagem, desde a Educação Básica até o Ensino Superior, visando ao letramento, com ênfase nos procedimentos didáticos. Precisa, por exemplo, utilizar textos com figuras ou desenhos ilustrativos, de acordo com a proposta de Hughes (1998, p.116), que explicita como é constituído o letramento visual, que perpassa as áreas curriculares:

- Ler imagens do entorno - sobretudo comerciais;

- Ler imagens de livros ilustrados;

- Usar imagens como apoio para leitura de textos simples;

- Ler sinais, símbolos e figuras no ambiente escolar/sala de aula, com objetivo de promover alfabetização;

- Criar imagens visuais significativas para registrar compreensão de tarefas;

- Usar figuras em textos de não-ficção como apoio da aprendizagem de conteúdo escolar;

- Ler a página - diferentes maneiras de apresentar o texto e as figuras.

Conforme posicionamento da autora, essas estratégias são bastante significativas e trazem resultados produtivos na sala de aula.

Partindo dessa perspectiva, é preciso que o corpo docente compreenda a singularidade linguística dos surdos. O decreto de Libras (BRASIL, 2005) propõe que 
o professor regente de classe tenha conhecimento acerca da singularidade linguística manifestada pelos alunos surdos, de modo que não sejam prejudicados por essa peculiaridade. O professor deve olhar os alunos surdos independentemente da sua condição auditiva, compreendendo a linguística dos aprendizes.

A realidade nos contextos escolares de modo geral nos mostra a dificuldade dos aprendizes surdos com relação às habilidades de leitura e escrita. Esse fato é preocupante e deve ser visto com muita atenção diante da exigência do padrão formal da Língua Portuguesa. É importante considerar a dificuldade do aluno surdo para produzir textos, muitas vezes, devido ao ensino inadequado da LP escrita e, principalmente, pela falta de hábito de ler, acarretando um vácuo na escrita.

Segundo Pereira e Karnopp (2003), é fundamental o aluno compreender o que lê, mas essa compreensão somente ocorrerá se ele tiver acesso à Língua Portuguesa de forma adequada, em consonância com o previsto no Decreto 5.626/2005, ao destacar que o ensino de Libras e de Língua Portuguesa deve ser ministrado em uma perspectiva dialógica, funcional e instrumental. Pereira e Karnopp (2003) ressaltam que o problema na educação de surdos não é a falta de conhecimento dos signos, mas o de não terem domínio dos significados das palavras e da estrutura da oração. Segundo as autoras:

\footnotetext{
Embora não apresentem dificuldade para decodificar os símbolos gráficos, grande parte não consegue atribuir sentido ao que lê. Essa dificuldade parece decorrer, principalmente, da falta de conhecimento da língua usada na escrita do português, no caso dos surdos brasileiros. A falta de conhecimento pode ser observada tanto em relação ao vocabulário quanto em relação às estruturas sintáticas. (PEREIRA e KARNOPP, 2003, p. 165).
}

Observa-se, portanto, a importância do trabalho do professor com alunos surdos. O interesse dos aprendizes por mídias digitais pode ser utilizado pelo professor como recursos e instrumentos de ensino. O uso de vídeos em língua de sinais também pode ser utilizado de modo a estimular o interesse dos aprendizes, deixando-os à vontade para ler e compreender textos e palavras e, assim, explorar o significado e o letramento. Didó (2012), ao abordar sobre o uso de mídias digitais na educação de surdos, destaca a importância da internet e do aparelho celular como ferramentas eficazes e ressalta que 
A internet, assim, tem um papel preponderante nesse avanço de qualidade de vida, comunicação e mudança social dos surdos. Através do acesso a ela, o surdo pode apropriar-se mais facilmente da informação, aprendendo muito mais, num tempo e esforço muito menores. (DIDÓ, 2012, p. 29).

Savedra (2009, p. 90) destaca quatros pontos cruciais que prejudicam a aprendizagem de alunos surdos: "o não uso da LIBRAS e a falta de conceitos; a não compreensão da Língua Portuguesa; o acesso restrito à informação; a falta de conhecimento científico."

Pereira (2007) revela que a aquisição da Língua Portuguesa visa a ampliar o conhecimento linguístico:

Na medida em que adquiram a Língua Portuguesa, faz-se necessário que os alunos tenham acesso a materiais escritos, de diferentes gêneros e tipos textuais, para que ampliem seu conhecimento lingüístico e textual e assim, possam não só ampliar suas habilidades de compreensão como também de produção de textos. (PEREIRA, p.142, 2007).

Segundo a referida pesquisadora, é importante rever habilidades de compreensão textual no sentido de vivenciar o universo que está sendo inserido, quanto mais acesso a textos diferenciados melhor para alunos surdos e ouvintes dando-Ihes visibilidade sobre abordagens, temáticas, enfim, ao se ampliar conhecimento, facilitará a produção da escrita. O papel do professor é fundamental no sentido de estimular os alunos a aprimorar suas habilidades de leitura e escrita.

Tendo em vista essas reflexões sobre a escolarização inclusiva e o ensino de Língua Portuguesa escrita, este artigo busca mostrar análises de produção escrita de alunos surdos no Ensino Médio, destacando sua proficiência no português escrito, ou seja, se houve aprendizagem de forma significativa, considerando-se que são alunos do Ensino Médio, que já passaram por vários anos de escolaridade. Busca-se, também, avaliar a influência da leitura para a construção do conhecimento de mundo, o que pode ser observado nas produções textuais escritas.

A seguir, serão apresentados os procedimentos da pesquisa.

\section{Tipo de pesquisa}

A metodologia de pesquisa utilizada neste trabalho é o estudo de caso, cujo conceito é apresentado por Yin (2005, p. 32) como um 
[...] estudo empírico que investiga um fenômeno atual dentro do seu contexto de realidade, quando as fronteiras entre o fenômeno e o contexto não são claramente definidas e no qual são utilizadas várias fontes de evidência. (YIN, 2005, p. 32)

A escolha por esse método de pesquisa é motivada pela experiência da profissional, enquanto observadora e participante do processo de ensinoaprendizagem, ao participar ativa e diretamente desse processo, juntamente com os alunos surdos, buscando contribuir para o desenvolvimento das habilidades de leitura e escrita e intermediando a comunicação entre eles e a professora titular, através da Língua Portuguesa e da Libras.

\subsection{0 contexto analisado - escolas e aprendizes surdos}

Esta pesquisa ocorreu em 2016, mais especificamente entre os meses de junho e setembro, em duas escolas públicas estaduais, localizadas em Nilópolis, Rio de Janeiro. Nessa época, ambas ofereciam ensino em turmas inclusivas, sendo que os docentes não usavam Libras, mas se comunicavam com os alunos surdos por leitura labial. Para suprir essa lacuna da língua de sinais, havia tradutores intérpretes de Libras, embora a permanência desses profissionais tenha sido curta na escola, em virtude da demissão de muitos por conta da crise financeira do Estado. A falta de tradutores intérpretes causou grande prejuízo aos alunos surdos. Além de pesquisadora, a autora deste artigo atuou como intérprete de Libras no Ensino Médio em uma dessas escolas.

Como dito anteriormente, o foco deste trabalho é apresentar a análise das produções escritas de alunos do Ensino Médio, buscando avaliar sua proficiência em Língua Portuguesa escrita e seu conhecimento de mundo. Como se trata de uma pesquisa realizada durante um curso de pós-graduação, foram cumpridas as exigências da instituição de ensino (INES): documentação preenchida e assinada por todos os envolvidos: gestores e alunos das escolas, assim como a dos gestores do INES. Os informantes da pesquisa (Alunos A, B, C) autorizaram a divulgação dos seus registros e assinaram Termo de Consentimento Livre e Esclarecido (TCLE). Visando resguardar a identidade dos informantes, foram tomados cuidados éticos, por exemplo, não exposição do aluno em filmagem ou gravação, uso de nomes fictícios, mantendo a imparcialidade e a identidade. 
A seguir será apresentada uma síntese sobre esses participantes da pesquisa:

\begin{tabular}{|l|l|}
\hline $\mathbf{1}^{\circ}$ ano & $\begin{array}{l}\text { Aluno A - } 19 \text { anos, oralizado e fluente em Libras. Demonstra bastante } \\
\text { interesse por assuntos relacionados a esporte, principalmente, futebol. É } \\
\text { comunicativo com os colegas da turma e tem boa interação entre eles. No } \\
\text { Ensino Fundamental I e II, estudou na escola Municipal de Anchieta/Rio de } \\
\text { Janeiro. Estudou na escola Estadual Antonio Filgueiras Almeida, cursava no } \\
1^{\circ} \text { ano do Ensino Médio, no Município de Nilópolis. }\end{array}$ \\
\hline $\mathbf{2}^{\circ}$ ano & $\begin{array}{l}\text { Aluno B - } 21 \text { anos, oralizado e fluente em Libras. É simpático, brincalhão e } \\
\text { comunicativo e tem boa interação com os colegas ouvintes da turma. } \\
\text { Estudava na Escola Municipal de Nilópolis, na qual concluiu no Ensino } \\
\text { Fundamental II. Estudou na escola Estadual Bertha D Alessandro, cursava } \\
2^{\circ} \text { ano do Ensino Médio, no Município de Nilópolis. }\end{array}$ \\
\hline $\mathbf{3}^{\circ}$ ano & $\begin{array}{l}\text { Aluna C - 19 anos, oralizada. Embora conheça Libras, descarta o uso dessa } \\
\text { língua e prefere se comunicar por meio de oralização. Apresenta boa relação } \\
\text { com os colegas ouvintes. No Ensino fundamental I, estudou na Escola } \\
\text { Municipal de João de Meriti I e, no Ensino Fundamental II, estudou na escola } \\
\text { Estadual Bertha D Alessandro até concluir o Ensino Médio, no Município de } \\
\text { Nilópolis. }\end{array}$ \\
\hline
\end{tabular}

Quadro 1: Dados dos participantes da pesquisa

\subsection{A pesquisadora}

Na turma do $1^{\circ}$ ano do Ensino Médio, atuava com a função de Intérprete de Libras, acompanhando também o aluno surdo (Aluno A) na sala de aula, o qual apresentava pouco conhecimento e tinha dificuldade de compreender determinadas atividades. Fui apresentada ao aluno do $2^{\circ}$ ano do Ensino Médio (Aluno B) como pesquisadora, embora o aluno havia pensado que estava lá para trabalhar, já que ele estava sem intérprete de Libras. Na turma do $3^{\circ}$ ano do Ensino Médio, a Aluna C estava presente na escola, mas sem acompanhamento de intérprete de Libras.

Na próxima seção, será apresentada a análise dos dados referentes à produção textual dos alunos surdos no Ensino Médio e sua discussão.

\section{Análise dos dados e discussão}

Vale destacar o limitado repertório linguístico, a pequena prática de hábitos de leitura e o uso recorrente da língua na variedade informal no cotidiano dos alunos. A experiência como intérprete e como observadora revela que esses alunos não 
demonstram muito interesse por leitura, mas sim pelo uso da tecnologia, ao acessarem mídias sociais como facebook, whats app e redes sociais, nas quais predominam palavras abreviadas e bastante informais. Demonstram interesse também por vídeos em Libras.

Ao serem perguntados se foram incentivados pelos pais para desenvolverem algum tipo de leitura, disseram que não e relataram que as palavras em português são difíceis e que têm dificuldades para entender os significados. Esse dado revela a importância de o professor trabalhar vocabulário com alunos surdos.

Com relação às produções textuais, conforme já sinalizado, fazem parte do corpus da pesquisa produções textuais de alunos surdos do Ensino Médio, oriundos de duas escolas estaduais no município de Nilópolis - RJ. A seguir, serão apresentados os dados obtidos nas análises dos textos dos alunos surdos.

\section{$\checkmark \quad 1^{\circ}$ ano do Ensino Médio - Aluno A}

Para essa produção textual, a professora de Língua Portuguesa entregou a prova para turma, constituída por duas questões de múltipla escolha e a terceira questão com proposta de redação sobre tema livre, ou seja, os alunos podiam escolher o tema que desejassem. O tema escolhido pelo Aluno A foi "Futebol". Como sinalizado anteriormente, o tema esporte é um dos prediletos desse aluno e representa umas das atividades de que ele mais gosta de praticarr juntamente com os amigos ouvintes. Vejamos o texto produzido por ele ${ }^{2}$.

Figura 1: produção escrita do Aluno A - Primeiro ano do Ensino Médio

De acordo com a escrita do Aluno A, compreende-se que ele ama jogar futebol e narra sobre uma combinação com os amigos ouvintes para uma partida em um lugar chamado "Monteiro" e "Roma", locais próximos de sua residencia, conforme foi mencionado pelo aluno.

Em outro momento da redação, ele faz uma referência à identidade surda, quando destaca a palavra "mudo" e exige respeito para com ele. Vale ressaltar que a palavra "mudo" foi utilizada durante muito tempo, mas está ultrapassada e essa

2 O texto do aluno foi transcrito exatamente como produzido originalmente. 


\section{Futebol}

O amigo foi chamado comigo de marcou futebol a lugar "Monteiro". Mas muito pessoas os ouvintes gostou ao união é os surdos quer aprender fubal preciso ajudar queria melhoras.

Meu irmão queria saber surdo e o Fábio jogar bem poderia de futebol no flamengo o meu irmão gostou ver o Fábio de futbal. O primo quer ver de futebol a lugar "Roma" que jogando o Fábio gostou os ouvintes mas uma pessoa é ouvinte não gostou surdo, porque ouviu falando a palavra "Mudo" mas Fábio saber falar preciso me respeito queria jogar aprender.

Meu amigo chamado queria sabia poder o jogador os surdos de futuro no Brasil, mas aprender muito melhor estudar depois poder jogar no flamengo os surdos queria muito feliz, Fábio muito parabéns conguir jogador de futebol.

revelação do aluno mostra sua consciência com relação às transformações na educação de surdos e à identidade surda, pois durante muitas gerações utilizou-se a expressão surdo-mudo de forma generalizada. Após movimentos que levantaram a bandeira em prol dos surdos, principalmente da comunidade surda, adotou-se a terminologia modificada como "Surdo". Nesse caso, por ser surdo, ele insinua que precisa ser respeitado, mesmo sendo surdo.

É importante verificar o reconhecimento do Aluno A com relação aos "estudos". Mesmo sonhando em ser jogador de futebol, ele destaca que é mais importante concluir os "estudos" e projetar para o futuro o sonho de ser jogador de futebol. Essa consciência sobre a importância da formação escolar (na Educação Básica, formação acadêmica, formação escolar, etc) poderia ser mais argumentada pelo aluno, porém, ele provavelmente ele não desenvolveu melhor o parágrafo devido à falta ou limitação de repertório linguístico em Língua Portuguesa.

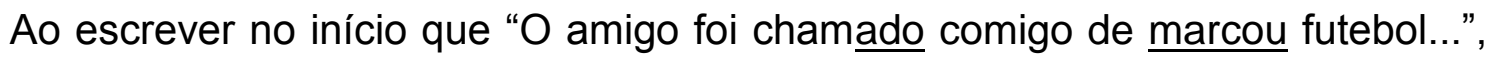
demonstra conhecer flexão verbal mais complexa, usando o tempo verbal no particípio (foi chamado) e no passado (marcou), usando corretamente a flexão na terceira pessoa no singular. Isso mostra o uso adequado, ou seja, ele conhece a construção verbal, mas não usou adequadamente na oração (foi chamado). Esse dado pode nos levar a crer que o Aluno A sabe da existência da palavra, mas não se apropriou do seu uso adequado na L2.

Considerando-se que a produção textual desse aluno é realizada em $\mathrm{L} 2$, o aluno parece ter noção da organização de elementos na estrutura da frase de LP como L1, ao usar, por exemplo, as construções “o amigo", "muitas pessoas”, "meu irmão”. Além 
disso, usa verbos no passado, inclusive a locução verbal "foi chamado"; flexão verbal no futuro do pretérito "poderia"; e tempos verbais corretos no passado, como "gostou", "não gostou”, "queria”. Quando cita o nome Fábio, poderia ter substituído por "Eu”.

Com relação ao uso de preposição, demonstra conhecer, mas não muito o sentido funcional e o uso destes elementos: "futebol a lugar Roma", "poderia de futebol", "ver de futebol". Isso mostra que o aluno está na interlíngua, porque em língua de sinais, o uso da preposição está incutido ou implícito no sinal, na configuração de mãos ou em classificadores.

O emprego de conjunções parece mais evoluído porque o aluno usa as conjunções mas e porque adequadamente, por exemplo: “... que jogando o Fábio gostou os ouvintes mas uma pessoa ouvinte não gostou o surdo, porque ouviu falando...". Podemos ver também que o aluno usa pontuação correta antes da conjunção porque, demonstrando conhecer essa particularidade da Língua Portuguesa escrita.

Os dados apresentados na análise revelam que o Aluno $\mathbf{A}$ teve acesso à Língua Portuguesa escrita, no entanto, precisa de estímulos com relação ao aprimoramento das habilidades de leitura e escrita. Sobre isso Guarinello (2007) destaca que:

\footnotetext{
O domínio do português escrito só acontecerá por meio de seu uso constante, assim, os surdos, como os ouvintes, precisam ter acesso aos diferentes tipos de texto escrito. Além disso, o trabalho com a escrita deve partir do que esses indivíduos já possuem, ou seja, a língua de sinais, pois é essa a língua que dará toda a base linguística para aprendizagem de qualquer língua. (GUARINELLO, 2007, p. 142)
}

Indo ao encontro da posição de Guarinello (2007), na produção escrita do Aluno A, é perceptível a transferência de características da língua de sinais. Para que esse aluno desenvolva a produção escrita, é importante que ele tenha contato com textos escritos para compreendê-los e desenvolver a habilidade de escrita em segunda língua.

\section{$\checkmark \quad 2^{\circ}$ ano do Ensino Médio - Aluno B}

A professora de Língua Portuguesa do segundo ano do Ensino Médio relatou que o Aluno B faltou a aula do dia em que ela passou atividade de produção escrita. Como dito anteriormente, nesta turma inclusiva, eram apenas dois alunos surdos, 
sendo que o outro aluno não estava presente na sala de aula, portanto a observação foi focada no Aluno B.

No dia em que a professora estava corrigindo atividade anterior com a turma, não havia intérprete e os alunos surdos preferiram ficar conversando com a autora deste artigo, que queria observar a aula. Então, como não havia nenhuma produção escrita dos alunos surdos, a pesquisadora recorreu à professora da disciplina de Artes, que havia passado uma tirinha para eles compreenderem.

A partir da tirinha, apresentada a seguir, o Aluno B fez a seguinte produção escrita (Fig. 3).

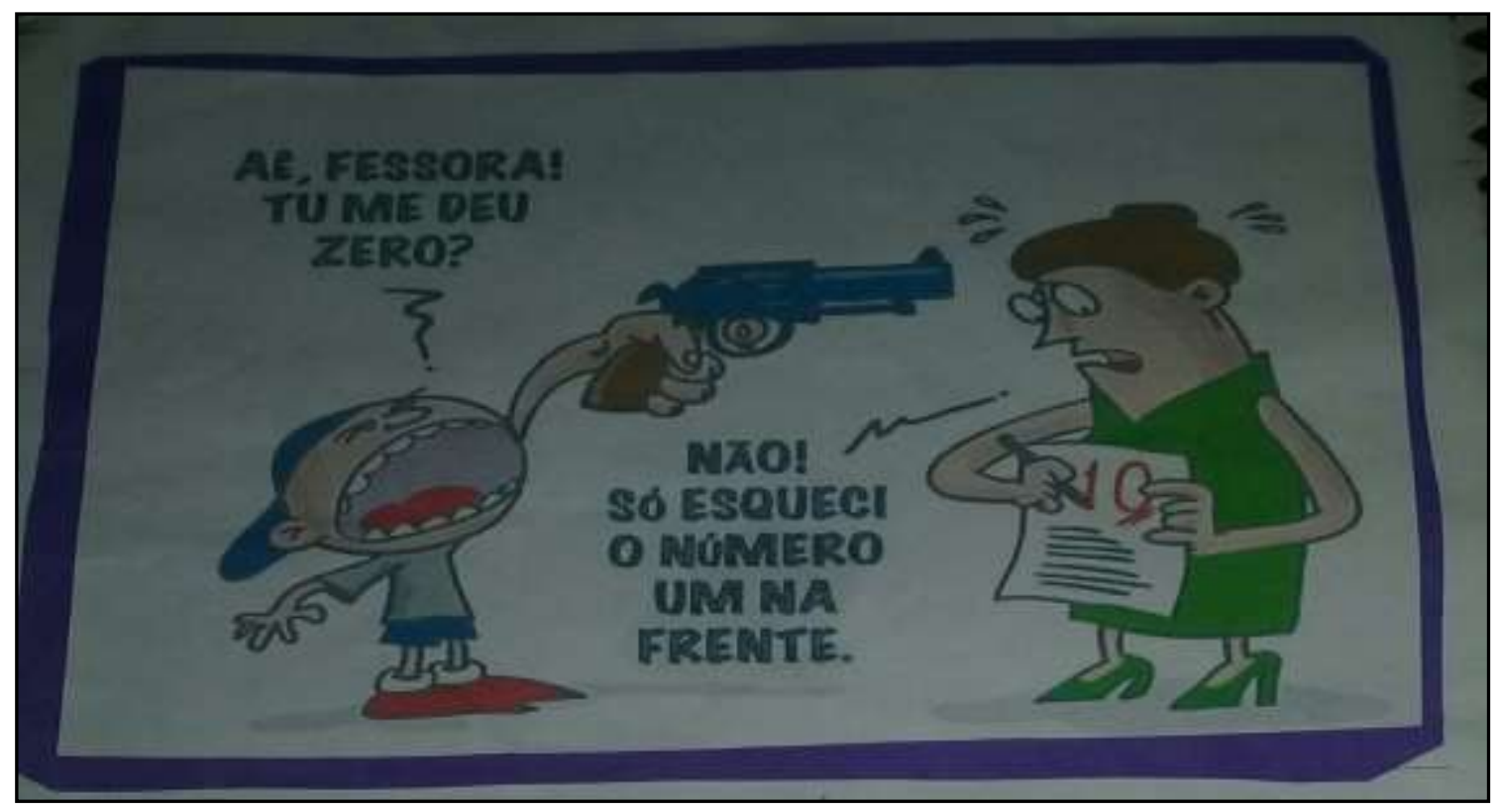

Figura 2: Tirinha
Eu precisar antes homem
Como antes falar
que vai está conversar
que esporte esta demais
ver EU precisa preparar estudar prova
wencia que fazer dificil mas esporte muito
é não quero sempre estudar nada e nota zero.

Figura 3: produção escrita do Aluno B - Segundo ano do Ensino Médio ${ }^{3}$

O contexto da tirinha mostra a revolta do aluno, questionando a professora sobre sua nota e ameaçando-a com a arma por causa da nota zero. A docente, pressionada

${ }^{3}$ Transcrição do texto do aluno B, exatamente como foi produzido por ele. 
e ameaçada, responde que a nota estava errada por uma questão do esquecimento, consertando-a na frente do aluno.

Com a observação "Eu ver precisa preparar estudar prova", nota-se a importância do preparo escolar. No final do texto, o raciocínio parece contraditório e demonstra a preocupação do Aluno $\mathbf{B}$ com relação à nota, veja que o aluno cita: "homem que fazer difícil esporte muito é quero sempre estudar nada e nota zero". O aluno traz a ideia sobre esporte de forma descontextualizada, pois não há nenhum referente ou relação com essa palavra na tirinha. Pode-se deduzir que seu raciocínio era de que a prática de esporte pode atrapalhar o estudo e, principalmente, quando se refere à nota da avaliação.

Observa-se que nessa atividade, o aluno não conseguiu compreender o sentido da tirinha. Talvez essa dúvida seja porque ele não tenha conversado com a professora sobre o texto e preferiu elaborar um texto sem focar nos significados explícito e implícito.

Outra questão importante refere-se à dificuldade do Aluno B em identificar o registro informal da Língua Portuguesa usado pelo personagem da tirinha. Essa percepção revelaria um amadurecimento do Aluno B com relação à variação linguística - formal/informal, por exemplo. Vale destacar que estamos diante de uma produção escrita de um aluno do Ensino Médio, cujo nível de escolaridade pressupõe prática de leitura mais frequente e conhecimento de mundo mais amadurecido do que o de um aluno de séries anteriores.

$\mathrm{Na}$ tirinha em questão e em leituras de tirinhas ou textos com significados implícitos, é necessário que o professor trabalhe os sentidos do texto, explore os tipos de informação verbal e não verbal, busque identificar e ampliar o conhecimento de mundo do aluno, principalmente do aluno surdo, tendo em vista que o texto para esse aprendiz está materializado em sua L2. Nesse caso, é imprescindível a contextualização dos textos, de modo que o aluno revele sua bagagem cultural e isso contribuirá para a construção de seus argumentos na produção escrita.

Com relação à parte linguística, em sua produção textual escrita, o Aluno B não usa pontuação, preposições, conectivos, diferentemente do Aluno A, que demonstra maior grau de conhecimento da $L 2$, tendo em vista a flexão verbal, o uso de conectivos e preposições e o uso de pontuação, mesmo em alguns registros incorretos. O Aluno 
B, portanto, parece ter mais dificuldade com relação ao desenvolvimento das habilidades de leitura e escrita.

Vale ressaltar também que esse aluno surdo adquiriu a Libras como L1 em sua trajetória de vida, o mesmo não aconteceu com a L2, necessitando, por isso, de um avanço, o que deveria ter-Ihe sido disponibilizado nas escolas e nas séries anteriores. Pode-se supor que ele não tenha tido reforço na escrita, na compreensão de conceitos, de vocabulário, dificultando-Ihe compreender, inclusive, determinada atividade proposta pelas (os) docentes. A título de informação, no dia da prova de Língua Portuguesa, com questões de múltipla escolha, a docente relatou que o Aluno B e o Aluno $\mathbf{C}$ faziam leitura rápida e marcavam qualquer opção, ignorando palavras cujo significados eles não sabiam, ou seja, desconheciam os conceitos.

\section{$\checkmark \quad 3^{\circ}$ ano do Ensino Médio - Aluna C}

A análise foi realizada em um texto escrito por uma aluna do terceiro ano do Ensino Médio, Aluna C. A experiência na turma dessa aluna ocorreu quando a docente da Língua Portuguesa havia solicitado à turma uma redação sobre a temática: Desigualdade Social entre homens e mulheres. A primeira produção textual dessa aluna foi desconsiderada porque a aluna copiou parte do texto de uma pesquisa divulgada em uma reportagem. Essa ocorrência pode ser explicada pelo fato de a aluna não dominar a temática abordada.

Então, foi-Ihe solicitada outra redação com tema livre, ou seja, poderia escrever sobre um assunto do seu gosto. A aluna escolheu o tema: Melhoria na Cidade de Nilópolis. A escolha pelo tema pode ser explicada pelo fato de ela morar nesse município e conhecer a região, principalmente, assuntos sobre criminalidade, violência, escassez de atendimento à saúde, entre outras razões. Diferentemente da produção textual anterior, a aluna produziu um texto autêntico, sem cópia.

A figura a seguir mostra a produção textual da Aluna $\mathbf{C}$. 


\section{Melhoria na Cidade de Nilópolis}

Muitas mudanças precisa ser feita em Nilópolis pós o que esse prefeito fez e deixou Nilópolis uma desordem, quando o novo prefeito for eleito pode transformar a cidade em uma nova e vai ter que consertar tudo o que atual prefeito fez uma desordem.

Eu gostaria que a violência acabassem, pois a violência aumentou, os assalto e os roubos também a desordem do atual prefeito aumentou pus cada destruição só vive aumentando.

Figura 4: Produção escrita da Aluna C - Segundo ano do Ensino Médio

Observando a escrita da Aluna C, pode-se notar que ela domina o tema, pois apresentou a situação atual do município, usando elementos como "desordem", "violência aumentou, os roubos e os assaltos também". Nesse sentido, fica implícita sua análise e destaque sobre as necessidades de melhorias: transformar Nilópolis em uma nova cidade e consertar o que o prefeito atual fez. No entendimento da Aluna $\mathbf{C}$, o novo prefeito deverá fazer algo para socorrer os moradores de Nilópolis, propondo mais segurança e melhoria na saúde.

No texto, pode-se observar que a aluna tem conhecimento de mundo e apresenta as ideias adequadamente em LP. Por exemplo, em “... precisa ser feita em Nilópolis pós o que esse prefeito fez e deixou Nilópolis uma desordem", chama atenção o seu argumento porque se coloca como moradora do local, consciente da realidade dramática e sem segurança. Por isso, ela repete a palavra "desordem" várias vezes, no intuito de reiterar seu posicionamento e a necessidade da atuação do novo prefeito.

É uma redação coerente e não demanda do leitor dificuldade para interpretar seus argumentos, pois ela se expressou adequadamente. Além disso, a produção textual da Aluna $\mathbf{C}$ revela conhecimento linguístico e conhecimento de mundo, ainda que a LP seja sua L2, utilizando corretamente a maioria das construções verbais: "precisa $(m)$ ser feita", "prefeito fez e deixou", "quando o novo prefeito for eleito", "Eu gostaria que a violência acabasse $(m)$ ". O fato de a aluna ter perdido a audição tardiamente pode explicar essa desenvoltura em LP escrita, uma vez que teve acesso a essa língua por algum tempo. 


\section{Considerações finais}

A aquisição da L2 pelo surdo é um processo de longo prazo para a maioria dos alunos e demanda de professores estratégias de ensino adequadas, buscando participar da construção e do aprimoramento de saberes, ou seja, considerando as especificidades do aprendiz e descartando discursos de que o aluno é incapaz de desenvolver habilidades de leitura e escrita na segunda língua.

Certamente, se os alunos aqui analisados tivessem recebido um acompanhamento mais intensivo e direcionado na época escolar adequada, teriam mais condições de produção textual. Os alunos surdos inclusos deveriam ter atendimento especializado para possibilitar seu aprendizado em L2, com a presença de profissional capacitado para trabalhar a língua dos surdos, que não imponha a língua padrão, mas que proporcione a construção do conhecimento, que possa tornar acessível desvendar conceitos, vocabulários, cultura, conhecimento de mundo e conhecimento prévio, sendo tudo estimulado pela leitura, despertando os seus interesses.

Em relação aos docentes, devem propor estratégias de ensino de LP como L2 para que os alunos não sejam prejudicados no desenvolvimento de habilidades de leitura e escrita, tornando-se capazes de compreender diferentes textos e diferentes gêneros textuais. Além disso, o professor dever promover a avaliação desses alunos a partir de um olhar diferenciado, contemplando a $L 1$ e a $L 2$, por meio de recursos apropriados para esses aprendizes.

Os profissionais devem buscar desenvolver incentivos, orientações e ferramentas que ajudem os alunos surdos a terem acesso à informação em todos os sentidos e acreditem na sua capacidade de continuar sua trajetória estudantil de forma digna, respeitando o par linguístico Libras-Língua Portuguesa e as singularidades linguísticas. O interesse dos alunos por mídias deve ser considerado efetivamente pelo professor, utilizando-as como recursos e instrumentos de ensino. O uso de vídeos em língua de sinais também pode ser utilizado de modo que o professor estimule os aprendizes, deixando-os à vontade para ler e compreender textos e palavras e, assim, explorar o significado e o letramento. 


\section{Referências Bibliográficas}

BRASIL. Lei 9.394, de 20 de dezembro de 1996. Estabelece as Diretrizes e Bases da Educação Nacional. Brasil. In: Diário Oficial da União. Ano, n 248, de 23 dez. 1996. Disponível em: <http://portal.mec.gov.br/seesp/arquivos/pdf/lei9394_ldbn1> Acesso em: 5 maio 2007.

BRASIL. Lei 10.436, de 24 de abril de 2002. Dispõe sobre a Língua Brasileira de Sinais - Libras e dá outras providências. Diário Oficial da União, Brasília, 25 abr. 2002. Disponível em: <www.portall.mec.gov.br/seesp/arquivos/pdf/lei10436> Acesso em: 5 julho 2010.

BRASIL. Decreto 5.626, de 22 de dezembro de 2005. Regulamenta LEI nํ⒑ 436, de 24 de abril de 2002, que dispõe sobre a Língua Brasileira de Sinais - Libras, e o art. 18 da Lei no 10.098, de 19 de dezembro de 2000. Diário Oficial da União, Brasília: 23 dez. 2005. Disponível em: <www.portall.mec.gov.br/seesp/arquivos/pdf/dec5626>. Acesso em: 5 julho 2010.

\section{Política Nacional de Educação Especial na Perspectiva da Educação} Inclusiva. Brasília: MEC/SEESP, 2008. Disponível em: [portal. mec.gov.br/seesp/arquivos/pdf/política] Acesso em:10 Abr. 2012.

CAMPOS, M. L. S. de. As funções da escrita na perspectiva do letramento como prática social. 2004146f. Dissertação (Mestrado em Educação nas Ciências) Universidade Regional do Noroeste do Estado do Rio Grande do Sul, ljuí, 2004.

CRUZ, O. M. S. S. Estratégias didáticas para o ensino de resenha acadêmica a graduandos surdos em uma perspectiva bilíngue: libras e língua portuguesa escrita. In: Márcia Moraes. (Org.). Estratégias didáticas para o ensino de resenha acadêmica a graduandos surdos em uma perspectiva bilíngue: libras e língua portuguesa escrita. $1^{a} e d$. Rio de Janeiro: Ventura, 2016, v. , p. 135-159.

DIDÓ, N. As mídias digitais na educação de surdos: a contribuição do telefone celular. Monografia de conclusão de curso de especialização. Universidade Federal do Rio Grande do Sul. 64 páginas.

HUGHES, P. Exploring visual literacy across the curriculum. In: EVANS, J. What in the picture books. Londres: Paul Champman Publishing, 1998.

LODI, A. C. B.; MOURA, M. C. Primeira língua e constituição do sujeito: uma transformação social. ETD - Educação Temática digital, Campinas, v.7 n.2, p.1-13, jun.2006 - ISSN: 1676-2592. Disponível em: <www.ssoar.info/ssoar/files/2010/657/artigo001> Acesso em: 10 junho 2010.

LODI, A. C. B. A leitura como espaço discursivo de construção de sentidos: Oficinas com surdos. 2004, 282f. Tese (Doutorado em Lingüística Aplicada e Estudos da Linguagem). Pontifícia da Universidade de São Paulo, São Paulo.

MAZZOTTA, Marcos J.S. Trabalho docente e formação de professores de educação especial. São Paulo: EPU, 1993. 
PEREIRA, M. C. da C.; KARNOPP, L. B. Leitura e Surdez. Letras de Hoje, Porto alegre, v.39, n.3, p.165-177, set 2003.

PEREIRA, M. C. C. A língua escrita como segunda língua: uma experiência de letramento. Congresso INES: 150 anos no Cenário da educação Brasileira. De 26 a 28 de setembro de 2007. (org.) INES. Divisão de Estudos e Pesquisas, Rio de Janeiro.

QUADROS, R. M. Inclusão de surdos: pela peça que encaixa nesse quebra-cabeça. Ensaios pedagógicos. Brasília: Ministério da Educação, Secretaria de Educação Especial, 2007.

SAVEDRA, R. A inclusão do surdo na sociedade atual do conhecimento científico. Congresso INES: Múltiplos Atores e Saberes na Educação Brasileira. De 23 a 25 de setembro de 2009 (org.) INES. Divisão de Estudos e Pesquisas, Rio de Janeiro.

UNESCO. Declaração de Salamanca: sobre princípios e práticas na área das necessidades educativas especiais. Brasília: CORDE, 1994. Disponível em: [portal.mec.gov.br/seesp/arquivos/pdf/salamanca] Acesso em: Mai 05.2007.

YIN, Robert K. Estudo de caso: planejamento e métodos. $3^{\mathfrak{a}}$ ed. Porto Alegre: Bookman, 2005. In: GIL, Antonio C. Métodos e técnicas de pesquisa social. 6. Ed. - 2. Reimpr. - São Paulo: Atlas, 2009.

\begin{abstract}
Sobre as autoras:
Osilene Maria de Sá e Silva da Cruz

Graduada em Letras - Português/Inglês (AEDB), especialista em Atualização Pedagógica (UFRJ), mestre em Estudos Linguísticos/Estudos de Tradução (UFMG) e doutora em Linguística Aplicada e Estudos da Linguagem (PUC-SP). No Instituto Nacional de Educação de Surdos (INES) é professora Adjunta de Língua Portuguesa como L1 e L2 para o curso de Pedagogia modalidades presencial e online. Também atua como professora e orientadora nos cursos de Pós-graduação lato sensu Educação bilíngue: uma perspectiva bilíngue em construção e Práticas de ensino leitura e escrita para surdos. Na Universidade Federal Fluminense (UFF), participa como docente e orientadora do curso de Mestrado Profissional em Diversidade e Inclusão (CMPDI). É líder dos grupos de pesquisa: Compreensão e Produção escrita por alunos surdos e O Passado tem história - análise discursiva sobre a representatividade do INES à luz da Linguística Sistêmico-Funcional. Os interesses por pesquisa envolvem ensino e aprendizagem de Língua Portuguesa para alunos surdos e para ouvintes, ensino de Língua Inglesa, tradução (produção e processo), cultura surda, gêneros acadêmicos, escrita acadêmica e profissional.

\section{Leila Lopes de Queiroz Gouveia}

Possui graduação em Pedagogia Bilíngue pelo Instituto Nacional de Educação de Surdos (INES). É pós-graduada Educação Especial/Inclusiva pela Universidade Cândido Mendes (UCAM) e em
\end{abstract}


Educação de Surdos - uma perspectiva bilíngue em construção (INES). Atualmente, participa de um curso de Especialização em Docência de Libras ((UNINTESE) e atua como intérprete de LIBRAS na Prefeitura de Belford Roxo e na Associação dos Tradutores/Intérpretes de Língua Brasileira de Sinais do Rio. Tem interesse pela temática da área da surdez e da educação de surdos, pela educação inclusiva e pelo ensino de Língua Portuguesa (leitura e escrita) para surdos. 